\title{
HUBUNGAN INDEKS MASSA TUBUH (IMT) DENGAN RESIKO KAKI DIABETIK PADA PASIEN DIABETES MELITUS TIPE 2
}

\author{
Tini \\ Jurusan Keperawatan, Poltekkes Kemenkes Kaltim \\ Email : tinizr17@gmail.com
}

\begin{abstract}
Increased incidence of diabetes mellitus also resulted in increased complications, one of them diabetic foot. Diabetic foot can be caused by various risk factors such as obesity factors characterized by high body mass index (BMI). This study aims to determine the relationship between of body mass index (BMI) with the risk of diabetic foot in patients with type 2 diabetes mellitus.

This research uses correlational analytic design with cross sectional approach. Respondents were 68 people taken by purposive sampling. Body mass index is calculated from the measurement of body weight and height calculated through the formula BB / TB2. While the risk of diabetic foot is taken through diabetic foot screening risk screening with Inlow's 60 second diabetic foot Screening Tools from the Canadian Association of Wound Care.

The results showed that most respondents had IMT $\geq 23(73.5 \%)$ and low risk of diabetic foot $(67,6 \%)$. Statistical analysis with Chi square test obtained no relation between body mass index (BMI) with diabetic foot risk ( $p$ value 0,245 ). Despite low risk for diabetic foot, there are some risk factors that the patient has, including the use of the wrong footwear, the tingling and the neuropathy. So it is necessary to control blood sugar levels through weight control and foot care.
\end{abstract}

Keyword : body mass index, diabetes mellitus, diabetic foot risk

\section{Abstrak}

Meningkatnya kejadian diabetes melitus mengakibatkan pula meningkatnya komplikasi, salah satunya kaki diabetik. Kaki diabetik dapat disebabkan oleh berbagai faktor resiko diantaranya adalah faktor kegemukan yang ditandai dengan tingginya indeks massa tubuh (IMT). Penelitian ini bertujuan untuk mengetahui hubungan antara hubungan indeks massa tubuh (IMT) dengan resiko kaki diabetik pada pasien diabetes melitus tipe 2.

Penelitian ini menggunakan rancangan analitik korelasional dengan pendekatan cross sectional. Responden berjumlah 68 orang yang diambil secara purposive sampling. Indeks massa tubuh diperoeh dari pengukuran berat badan dan tinggi badan yang dihitung melalui rumus BB/TB2 ${ }^{2}$ Sedangkan resiko kaki diabetik diambil melalui pemeriksaan skrining resiko kaki diabetik dengan Screening Tools Inlow's 60 second diabetic foot dari Canadian Association of Wound Care. 
Hasil penelitian menunjukkan bahwa sebagian besar responden memiliki IMT $\geq 23(73,5 \%)$ dan beresiko rendah terjadinya kaki diabetik $(67,6 \%)$. Analisis statistik dengan uji Chi square diperoleh tidak ada hubungan antara indeks massa tubuh (IMT) dengan resiko kaki diabetik ( $p$ value 0,245). Meskipun beresiko rendah untuk mengalami kaki diabetik, namun terdapat beberapa faktor resiko yang dimiliki oleh pasien diantaranya penggunaan alas kaki yang salah, adanya kesemutan dan neuropati. Sehingga perlu dilakukan pengendalian kadar gula darah melalui pengontrolan berat badan dan perawatan kaki.

Kata kunci : indeks massa tubuh, diabetes melitus, resiko kaki diabetik

\section{PENDAHULUAN}

Diabetes melitus merupakan salah satu penyakit tidak menular (PTM) yang kejadiannya semakin meningkat dari tahun ketahun. Data dari International Diabetes Federation mencatat pada tahun 2014 terdapat 387 juta kasus dengan tingkat prevalensi global diabetes melitus mencapai $8,3 \%$. Centers for Disease Control and Prevention (2014) menyatakan bahwa kejadian diabetes melitus tipe 2 (NIDDM) sekitar 90-95\% dari populasi diabetes, yaitu jenis penyakit diabetes melitus yang disebabkan oleh gangguan sekresi dan resistensi hormon insulin.

Riset Kesehatan Dasar (2013) menunjukkan terjadi peningkatan kasus diabetes melitus di Indonesia dibanding data tahun 2007 yaitu dari 1,1\% menjadi 2,1\%. Terdapat sekitar 12 juta penduduk yang mengalami diabetes melitus dan diantaranya hanya 3 juta orang yang terdiagnosis (Pusdatin Kemenkes RI, 2014). Hasil Riskesdas (2013) juga mencatat adanya peningkatan kasus di Provinsi Jawa Barat sebesar 2\% dibanding pada tahun 2007 yaitu sebesar 1,4\%. Begitu halnya di Kota Bandung sebagai ibu kota, dimana Puskesmas Garuda merupakan salah satu puskesmas yang memiliki jumlah pasien diabetes melitus terbanyak.

Meningkatnya kejadian diabetes melitus menyebabkan angka komplikasi juga semakin meningkat, salah satunya adalah kaki diabetik. Komplikasi kaki diabetik berkontribusi terhadap mortalitas dan morbidisitas pasien diabetes melitus yang mengakibatkan peningkatan beban fisik, psikologis dan keuangan untuk pasien dan masyarakat pada umumnya. Diperkirakan 24,4\% dari total anggaran pelayanan kesehatan populasi diabetes melitus berhubungan dengan komplikasi kaki (Al Rubean, Derwish \& Ouizi et al, 2015). Prevalensi kejadian kaki diabetik di Indonesia sebesar 15\% dan sering berakhir dengan kecacatan bahkan kematian (Fatimah, 2015). Sehingga perlu adanya upaya deteksi dini terhadap faktor resiko terjadinya kaki diabetik melalui skrining kaki. Skrining kaki dilakukan agar seseorang dapat 
mengetahui resiko terjadinya kaki diabetik untuk menghindari komplikasi lebih lanjut (Tini, 2017).

Kaki diabetik dapat terjadi karena adanya berbagai faktor resiko, diantaranya faktor kegemukan. Obesitas atau kegemukan merupakan salah satu masalah kelebihan gizi yang dapat mempengaruhi produktivitas kerja (Wahyuni, 2010). Kejadian obesitas dapat diketahui dengan menghitung indeks massa tubuh (IMT). Seseorang dikatakan obesitas jika indeks massa tubuhnya $\geq 23 \mathrm{~kg} / \mathrm{m}^{2}$. Terdapat korelasi bermakna antara obesitas dengan kadar glukosa darah, yaitu derajat kegemukan IMT $>23$ dapat menyebabkan peningkatan kadar glukosa darah menjadi 200 mg\% (Fatimah, 2015).

$$
\text { Keadaan obesitas dapat }
$$

membuat resistensi insulin yang mengakibatkan aterosklerosis sehingga terjadi gangguan sirkulasi darah pada kaki yang dapat menyebabkan kaki diabetik. Penelitian Al Rubean, Derwish dan Ouzi et al (2015) menemukan bahwa obesitas merupakan faktor yang beresiko menyebabkan kaki diabetik. Begitu halnya penelitian Boyko et al (1999) yang juga menemukan bahwa seseorang yang memiliki berat badan $20 \mathrm{~kg}$ melebihi berat badan idealnya dapat beresiko mengalami kaki diabetik dengan nilai RR sebesar 1,2 (C195\%, 1,1$1,4)$.

Penelitian ini bertujuan untuk mengetahui hubungan antara indeks massa tubuh (IMT) dengan dengan resiko kaki diabetik pada pasien diabetes melitus tipe 2 di Puskesmas Garuda Kota Bandung.

\section{METODE}

Penelitian ini merupakan penelitian analitik korelasional dengan pendekatan cross sectional. Responden dalam penelitian ini berjumlah 68 responden yang diambil secara purposive sampling di Puskesmas Garuda Kota Bandung. Variabel independen dalam penelitian ini adalah Indeks Massa Tubuh (IMT) yang diperoleh dari pengukuran berat badan dan tinggi badan dan dihitung melalui rumus $B B(\mathrm{~kg}) / \mathrm{TB}^{2}(\mathrm{~m})$. terdapat 2 kategori IMT yaitu 1 jika IMT < 23 dan 2 jika $I M T \geq 23$. Sedangkan variabel dependen adalah resiko kaki diabetik yang diukur dengan menggunakan instrumen yang diadaptasi dari Screening Tools Inlow's 60 second diabetic foot dari Canadian Association of Wound Care. Hasil pemeriksaan selanjutnya dikategorikan menjadi 3 kelompok berdasarkan penelitian Lukita (2016) yaitu resiko rendah jika skor resiko kaki diabetik < 8 , resiko sedang dengan skor 8-16 dan resiko tinggi jika skor $>16$.

Instrumen yang digunakan dalam penelitian ini adalah lembar obeservasi pengukuran berat badan dan tinggi badan serta Inlow's 60second Diabetic Foot Screen Sreening Tool yang telah diuji validitas dan reliabilitasnya oleh Murphy, Laforet \& Da Rosa, et.al. (2012) pada 69 pasien diabetes melitus. Hasil uji menyatakan bahwa 
instrumen ini memiliki predictive validity dan reliabel. Nilai intrarater reliability pada pasien Long Term Care adalah 0,96 (kaki kanan) dan 0,97 (kaki kiri) dan pada pasien dialisis didapatkan 1,00 (kaki kanan dan kiri). Sedangkan untuk nilai interrater reliability pada pasien Long Term Care 0,92 (kaki kanan) dan 0,93 (kaki kiri) dan pada pasien dialisis 0,83 (kaki kanan dan kiri).

Penelitian ini menggunakan analisis univariat dan bivariat. Analisis univariat menggunakan distribusi frekuensi dan persentase. Sedangkan analisis bivariat menggunakan Chi Square karena data bersifat kategorik untuk melihat hubungan indeks massa tubuh (IMT) dengan resiko kaki diabetik.

\section{HASIL PENELITIAN}

Terdapat 68 responden dalam penelitian ini. Hasil penelitian menunjukkan rata-rata usia responden 60 tahun dan sebagian besar adalah perempuan (82,4\%). Tingkat pendidikan sebagian besar responden adalah SD (54,4\%) dan mengalami sakit diabetes melitus mayoritas selama 1-5 tahun $(47,1 \%)$.

Tabel 1 Distribusi Frekuensi Karakteristik Responden di Puskesmas Garuda Tahun 2017.

\begin{tabular}{|c|c|c|}
\hline Karakteristik & Jumlah & Prosentase (\%) \\
\hline Usia & \multicolumn{2}{|c|}{$\begin{array}{l}\text { Mean } \pm S D, \text { min-max } \\
60,59 \pm 8,5,38-81\end{array}$} \\
\hline Jenis Kelamin & & \\
\hline Laki-laki & 12 & 17,6 \\
\hline Perempuan & 56 & 82,4 \\
\hline \multicolumn{3}{|l|}{ Pendidikan } \\
\hline SD & 37 & 54,4 \\
\hline SMP & 14 & 20,6 \\
\hline SMA & 15 & 22,1 \\
\hline PT & 2 & 2,9 \\
\hline \multicolumn{3}{|l|}{ Lama sakit } \\
\hline$<1$ tahun & 6 & 8,8 \\
\hline 1-5 tahun & 32 & 47,1 \\
\hline $6-10$ tahun & 10 & 14,7 \\
\hline$>10$ tahun & 20 & 29,4 \\
\hline
\end{tabular}

Tabel 2 Distribusi Frekuensi Indeks Massa Tubuh (IMT) Responden di Puskesmas Garuda Kota Bandung Tahun 2017.

\begin{tabular}{lcc}
\hline \multicolumn{1}{c}{ Indeks Massa Tubuh } & Jumlah & Prosentase (\%) \\
\hline $\mathrm{IMT}<23$ & 18 & 26,5 \\
$\mathrm{IMT} \geq 23$ & 50 & 73,5 \\
Total & 68 & 100 \\
\hline
\end{tabular}

Tabel 2 menunjukkan bahwa sebagian besar responden berada pada 
kategori IMT $\geq 23$ sebesar $73,5 \%$.

Tabel 3 Distribusi Frekuensi Resiko Kaki Diabetik Responden di Puskesmas Garuda Kota Bandung Tahun 2017.

\begin{tabular}{lcc}
\hline \multicolumn{1}{c}{ Resiko Kaki Diabetik } & Jumlah & Prosentase (\%) \\
\hline Resiko Rendah & 46 & 67,6 \\
Resiko Sedang & 22 & 32,4 \\
Resiko Tinggi & 0 & 0 \\
Total & 68 & 100 \\
\hline
\end{tabular}

Tabel 3 menunjukkan bahwa sebagian besar responden $(67,6 \%)$ memiliki resiko rendah terjadinya kaki diabetik.

Tabel 4 Analisis Hubungan Indeks Massa Tubuh (IMT) dengan Resiko Kaki Diabetik Responden di Puskesmas Garuda Kota Bandung Tahun 2017.

\begin{tabular}{cccccc}
\hline IMT & \multicolumn{4}{c}{ Resiko Kaki Diabetik } & P Value \\
& Resiko Rendah & \multicolumn{2}{c}{ Resiko Sedang } & \\
& Jumlah & $\%$ & Jumlah & $\%$ & \\
\hline IMT $<23$ & 10 & 55,6 & 8 & 44,4 & 0,245 \\
IMT $\geq 23$ & 36 & 72 & 14 & 50 & \\
\hline
\end{tabular}

Uji statistik : Chi Square

\section{PEMBAHASAN}

Hasil penelitian ini
menunjukkan tidak adanya hubungan antara indeks massa tubuh dengan resiko kaki diabetik pada responden di Puskesmas Garuda Kota Bandung dengan nilai p 0,245. Hasil ini tidak sejalan dengan beberapa penelitian yang telah dilakukan sebelumnya. Purwandari (2014) dalam penelitiannya menemukan bahwa terdapat korelasi antara indeks massa tubuh dengan kadar gula darah pasien diabetes melitus ( $p$ value 0,045). Ganong (2008) menjelaskan bahwa faktor kegemukan mengakibatkan penekanan jumlah reseptor insulin pada sel-sel tubuh, sehingga mengakibatkan keadaan meningkatnya kadar gula darah.

Penelitian lainnya yang dilakukan oleh Wahyuni, Hasneli dan Ernawaty (2018) juga menemukan bahwa kadar gula darah berhubungan dengan terjadinya gangren pada pasien diabetes melitus ( $p$ value 0,024). 
Kadar gula darah yang tidak terkendali dapat menyebabkan komplikasi kronik berupa neuropati serta penebalan tunika intima pembuluh darah besar dan kapiler. Hal ini menyebabkan aliran darah jaringan tepi ke kaki mengalami gangguan yang akhirnya berdampak pada terjadinya nekrosis dan ulkus diabetikum.

Merujuk pada tabel 2 diperoleh bahwa sebagian besar responden memiliki indeks massa tubuh $\geq 23$ (73,5\%). Hal ini menunjukkan bahwa responden mengalami kelebihan berat badan. Beberapa hal yang melatar belakangi keadaan ini diantaranya rata-rata responden dalam penelitian ini berusia 60 tahun ke atas dan sebagian besar responden adalah perempuan (82,4\%). Adanya proses menua mengakibatkan perubahan anatomis, fisiologis dan biokimia. Faktor usia lanjut dapat mengakibatkan keterbatasan mobilitas atau kurangnya aktifitas fisik yang dapat berdampak pada terjadinya kegemukan. Sehingga hal ini juga akhirnya dapat mengakibatkan terjadinya resistensi insulin dan gangguan toleransi glukosa (Sudoyo, 2009).

Begitu halnya dengan jenis kelamin perempuan, Sudoyo (2009) menyatakan bahwa perempuan beresiko mengalami diabetes 3-7 kali lebih tinggi dibanding laki-laki. Hal ini disebabkan secara fisik perempuan memiliki indeks massa tubuh lebih besar dibandingkan laki- laki (Purwandari, 2018). Tingginya indeks massa tubuh pada perempuan dapat diakibatkan oleh proses hormonal yang menyebabkan distribusi lemak mudah terakumulasi dan kurangnya aktivitas fisik dibanding laki-laki.

Hasil uji statistik menunjukkan tidak adanya hubungan antara indeks massa tubuh dengan resiko kaki diabetik pada responden ( $p$ value 0,245$)$. Hal ini dapat dipicu dari data yang diperoleh bahwa sebagian besar responden berada pada resiko rendah terjadinya kaki diabetik (67,6\%). Keadaan ini dijelaskan dari aspek durasi penyakit sebagian besar responden kurang dari 10 tahun, yakni pada rentang 1-5 tahun (47,1\%). Durasi penyakit menjadi salah satu faktor resiko terjadinya kaki diabetik. AlRubeaan, Derwish dan Ouizi, et al (2015) menyatakan bahwa pasien diabetes melitus dengan durasi penyakit > 10 tahun beresiko mengalami kaki diabetik dengan OR 7,2 . Hal yang sama juga dilaporkan oleh Chiwanga dan Njelekela (2015) yang menemukan durasi $>10$ tahun menjadi prediktor terjadinya kaki diabetik dengan OR 1.94.

Meskipun hasil yang diperoleh sebagian besar responden beresiko rendah terjadinya kaki diabetik. Namun hal tersebut tidak menjadi alasan bagi pasien diabetes untuk tidak melakukan pencegahan terjadinya komplikasi kaki diabetik, salah satunya dengan mengendalikan berat badan agar 
dapat mengontrol kadar gula darah. Resiko rendah memiliki nilai kurang dari 8 skor kaki diabetik, hasil ini didapat dari pemeriksaan kaki. Nilai tersebut juga mengindikasikan adanya beberapa faktor resiko untuk mengalami kaki diabetik, diantaranya penggunaan alas kaki yang salah, adanya keluhan kesemutan, neuropati sensorik. Adanya faktor resiko tersebut menjadi hal yang penting untuk tidak menjadi kompilkasi lebih lanjut.

\section{SIMPULAN}

Hasil penelitian ini menunjukkan tidak adanya hubungan antara indeks massa tubuh (IMT) dengan resiko kaki diabetik pada pasien diabetes melitus tipe 2. Hal ini dapat disebabkan berbagai kondisi dan faktor lainnya. Sehingga perlu adanya penelitian lebih lanjut terhadap faktor-faktor lainnya yang beresiko terhadap kejadian kaki diabetik dengan analisis multivariate. Adanya resiko yang dimiliki oleh responden meskipun rendah menunjukkan bahwa responden memiliki faktor resiko yang dapat berpotensi terjadinya kaki diabetik. Sehingga diharapkan dapat melakukan upaya pencegahan yang juga didukung oleh keluarga dan perawat dalam memotivasi pengendalian kadar gula darah dan perawatan kaki.

\section{DAFTAR PUSTAKA}

Al-Rubeaan, K., Derwish, M. A., Ouizi, S., Youssef, A. M.,
Subhani, S. N., Ibrahim, H. M., \& Alamri, B. N. (2015). Diabetic foot complications and their risk factors from a large retrospective cohort study. PLoS One, 10(5) doi: http://dx.doi.org/10.1371/journ al.pone.0124446

Chiwanga, S.F \& Njelekela, A.M. (2015). Diabetic foot : prevalence, knowledge and foot self- care practice among diabetic patient in Dar es Salaam, Tanzania- a cross sectional study. Journal of Foot And Ankle Researches. http://dx.doi.org/10.1186/s130 47-015-0080-y.

Dinas Kesehatan Kota Bandung. (2015). Profil Kesehatan Kota Bandung.

Tidak dipublikasikan.

Fatimah N. R. (2015). Diabetes melitustipe 2.Jurnal Majority. Vol 4. No. 5. Universitas Lampung.

Ganong. (2008). Buku Ajar Fisiologi Kedokteran. EGC. Jakarta.

International Diabetes Federation. (2013). IDF Diabetes Atlas. Brussels, Belgium; International Diabetes Federation.

Lukita. (2016). Pengaruh ROM Aktif Kaki terhadap Resiko Terjadinya Ulkus Kaki Diabetik 
pada Pasien Diabetes Melitus Tipe 2. Skripsi. Universitas Jember. Tidak Dipublikasikan.

Murphy CA., Laforet K., Da Rosa P., Tabamo $F$ \& Woodbury MG. (2012). Reliability and Predictive Validity of Inlow's 60-Second Diabetic Foot Screen Tool. Advances in Skin \& Wound Care. 25:261-6

Purwandari. (2014). Hubungan Obesitas dengan Kadar Gula Darah pada Karyawan di RS Tingkat IV Madiun. Jurnal No. 25 vol. 1. ISSN. 0854-1922.

Pusdatin Kemenkes RI. (2014). Situasi dan Analisis Diabetes.Jakarta.

Puskesmas Garuda. (2015). Laporan Tahunan. Tidak dipublikasikan.

Riskesdas. (2013). Riset Kesehatan Dasar. Badan Penelitian dan Pengembangan Kesehatan Kemenkes RI. Jakarta.
Riskesdas. (2013). Pokok-pokok Hasil Riset Kesehatan Dasar Provinsi Jawa Barat. Badan Penelitian dan Pengembangan Kesehatan Kemenkes RI. Jakarta.

Sudoyo. (2009). Buku Ajar IImu Penyakit Dalam. Internal Publishing. Jakarta.

Tini, Rahayuwati, L \& Yamin, M (2017). Program Edukasi Berbasis Kelompok tentang Perawatan Diri terhadap Penurunan Resiko Kaki Diabetik Pada Pasien Diabetes Melitus Tipe 2. Tesis. Universitas Padjadjaran. Bandung. Tidak Dipublikasikan.

Wahyuni, Hasneli \& Ernawaty. (2018). Hubungan Kadar Gula Darah dengan Tejdinya Gangren pada Pasien Diabetes Melitus. 